\title{
Adaptation of Learning Objects with Multi-Format Assets
}

\author{
Joab E. Agaba and Jude T. Lubega
}

\begin{abstract}
A good number of tools and techniques have been developed to support reuse of learning objects in instruction design for e-learning environments. However, the challenge is that learning objects with multi-format assets can not be fully adapted for reuse using existing adaptation tools and techniques. This limits reusability in instruction design. This research proposes a model to support full adaptation of learning objects with multi-format assets so as to improve reusability in instruction design.
\end{abstract}

Index Terms-Instruction design, learning objects, reusability, learning object adaptation.

\section{INTRODUCTION}

The term learning object has been defined by a number of scholars and standards organizations but the definitions focus on how the concept has been used in instruction design. For example, Wiley [1] defines a learning object as "any digital resource that can be reused to support learning", Chiappe et al. [2] defines a learning object as "a digital, self-contained, reusable entity with a clear learning aim that contains at least three internal changing components: content, instructional activities, and context elements", while the standard for Learning Object Metadata [3] developed by the IEEE's Learning Technology Standards Committee (LTSC) defines a learning object as "any entity - digital or non- digital - that may be used for learning, education or training". These definitions of a learning object suggest that anything used or reused in instruction design to achieve a learning objective can be a learning object. A learning objective in this case means " a single measurable (or verifiable) step on the way to a learning goal" [4].

However, for the purpose of scope, this research looks at learning objects that have the following key characteristics;

- Learning objects that are white-box transparent [5].

- Learning objects that can be delivered in a web-based environment.

- Learning objects which can be decomposed into their assets(but remain with a pedagogical sense) to allow adaptation.

- Learning objects whose metadata is stored in XML files for easy discovery in repositories according to the IEEE LOM metadata standard [6].

Schach [7] defines reuse as "using components of one product to facilitate the development of a different product with different functionality". Thus, in this paper we define

Manuscript received July 4, 2014; revised September 11, 2014

J. E. Agaba is with College of Computing and Information Sciences, Makerere University, Uganda (e-mail: jagaba@cit.mak.ac.ug).

J. T. Lubega is with School of Computing and Engineering, Uganda Technology and Management University, Uganda (e-mail: jlubega@utamu.ac.ug). reusability of learning objects as the likelihood that the learning object designed can be used in different ways to achieve different learning objectives with little or no modification.

The learning objects can be retrieved from the repositories and reused in creating instructional materials. Just as how reusing software components in components based software engineering improves on productivity and thus reducing the cost of software development [8], so should be the reuse of learning objects in instructional design. Agaba and Lubega [5] suggest that "as long as the terms and conditions of reusing the learning object are not violated by the instructional designer, reusing existing learning objects to produce new content saves a considerable amount of time and other resources that would have been required to design the instructional content from scratch".

Usually, the instructional designer hardly reuses the learning objects during instruction design without making modification or adaptation. According to Sanz-Rodriguez et al. [9], "the problems that reuse of learning objects must overcome are similar to those of other shared resources in repositories, such as images, software libraries or APIs". In addition to this, Ochoa and Duval [10], [11] suggest that the techniques applied in reusing shared resources from repositories can be applied in reusing learning objects.

In this paper, we look at adaptation of learning objects (with multi-format assets) for reuse in instruction design. Learning object assets in this case are the indecomposable (but reusable) building blocks of a learning object such as images, text snippets, audio/video clips, applets, among others. Existing learning object metadata standards such as IEEE LOM and SCORM consider learning object assets as the lowest level of granularity of the learning object.

The rest of this paper is organized as follows; Section II presents learning object adaptation for reuse, specifically looking at the adaptation process, the levels of adaptation and challenges with the present approaches for adaptation, Section III presents the proposed model for adaptation of learning objects with multi-format assets and Section IV presents the conclusions and future work.

\section{LEARNING OBJECT ADAPTATION FOR REUSE}

\section{A. Learning Object Adaptation Process}

In this research, we define learning object adaptation as the process of modifying the learning object for reuse in instruction design so as to achieve a new learning objective. Like software component adaptation, learning object adaptation process may involve the end-user (in this case the instructional designer) modifying the learning object by writing new source code that alters existing functionality or behavior of that learning object [12]. It should be noted that learning object adaptation is different from learning object 
evolution or learning object customization. In fact, with evolution, the author of the learning object changes it to produce a new version whereas for customization, the end-user adjusts the initial settings of the learning object from a given set of options [13].

The results of the mEducator project [14] showed that a learning object can be adapted into different contexts such as; the content itself, the language, the cultures, the pedagogical approaches, the educational levels, the disciplines or professions, the content types, the technology, and the people with different abilities.

\section{B. Levels of Learning Object Adaptation}

Usually, a standard-based learning object consists of two key parts, namely; the learning content and the metadata [1]. The content is what the author intends to deliver as knowledge to the learner while the metadata is the data about the content in the learning object aimed at making it easy to discover the learning object from the repositories [1]. Thus learning object adaptation can be either at content level or at metadata level.

\section{1) Learning object adaptation at content level}

At this level of adaptation, the instructional designer modifies existing instructional content of the learning object so as to reuse it in achieving a new learning objective in the learning environment. For example, a Java applet (as an example of a learning object) meant to teach the student how the while-loop in Java works (in form of a simulation) can be modified(if the source code is available) to teach the student how the do-while-loop works. The fact that this Java applet now achieves a new learning objective means that it has been adapted for reuse.

\section{2) Learning object adaptation at metadata level}

Available literature shows that different metadata standards have different metadata elements used to describe a learning object. For example, both the IEEE LOM standard and the CanCore standard use a set of 9 metadata elements to define the descriptive, structural and semantic features of a learning object while the Simple Dublin Core uses 15 elements [15]. However, the instructional designer may want to integrate or reuse two or more learning objects from different metadata standards into the instructional content. For example, integrating an IEEE LOM standard-based learning object with a Simple Dublin Core standard-based learning object. In such a situation, the instructional designer may require adaptation of the metadata to enable the learning objects integrate easily.

However, for purposes of scope, this research looks at adaptation of learning objects at content level.

\section{Challenges with Learning Object Adaptation}

Learning object adaptation as a process itself involves a number of challenges as observed by Wang et al. [16] and include the following;

- Non-technical instructors attempting to adapt the technical aspect of the learning object. For example, a non-Java programmer attempting to adapt an open source learning object written in Java. In such a case, lack of expertise may deny the instructional designer to achieve the intended learning objective.
- Version control of the adapted learning objects.

Other challenges with adaptation of learning objects may include

- Keeping with in the LOM metadata standards to allow interoperability of the adapted learning objects.

- Adapting a learning object with multi-format assets using an adaptation tool that supports one particular content format.

\section{Current Tools for Learning Object Adaptation}

TABLE I: SUMMARY OF A REVIEW OF THREE OF THE CURRENT TOOLS /

\begin{tabular}{|c|c|}
\hline $\begin{array}{c}\text { Learning Object } \\
\text { Adaptation Technique } \\
\text { /Tool }\end{array}$ & $\begin{array}{l}\text { Challenges with the tool/ } \\
\text { technique }\end{array}$ \\
\hline $\begin{array}{l}\text { The Wiki-type Content } \\
\text { Editor[16]. This is a } \\
\text { learning object adaptation } \\
\text { tool developed under the } \\
\text { MURLLO project to } \\
\text { support adaptation of } \\
\text { language learning objects } \\
\text { written in HTML format in } \\
\text { form of Web pages }\end{array}$ & $\begin{array}{l}\text { - Requires a technical } \\
\text { instructional designer to edit } \\
\text { HTML/CSS codes in the } \\
\text { learning object. } \\
\text { Only edits HTML/CSS codes } \\
\text { yet a learning object may } \\
\text { contain other assets like Java } \\
\text { applets which are linked to that } \\
\text { learning object through HTML } \\
\text { tags. In other words, it does not } \\
\text { state how a learning object with } \\
\text { multi-format assets can be fully } \\
\text { adapted. } \\
\text { Works on the assumption that } \\
\text { all the learning objects are } \\
\text { always in HTML/CSS. } \\
\text { Does not support integration of } \\
\text { learning objects with other } \\
\text { objects after adaptation. }\end{array}$ \\
\hline $\begin{array}{l}\text { Transformation } \\
\text { Augmentation and } \\
\text { Substitution (TAS) service } \\
\text { in LOTTI [17]. A learning } \\
\text { object adaptation technique } \\
\text { integrated in the LOTTI } \\
\text { tool developed by the } \\
\text { Accessibility Research } \\
\text { Center at the University of } \\
\text { Teesside. It is based on the } \\
\text { principle that learning } \\
\text { content } \\
\text { can be generated from } \\
\text { adaptable aggregations of } \\
\text { learning objects and media } \\
\text { components using proven } \\
\text { learning patterns. }\end{array}$ & $\begin{array}{l}\text { Does not state how a learning } \\
\text { object with multi-format assets } \\
\text { can be fully adapted. }\end{array}$ \\
\hline $\begin{array}{l}\text { The GiSHEO eLearning } \\
\text { Environment -eGLE [18] }\end{array}$ & $\begin{array}{l}\text { - The HTML/CSS editor requires } \\
\text { a technical instructor to adapt } \\
\text { the content. } \\
\text { - Also assumes that all learning } \\
\text { objects are written in } \\
\text { HTML/CSS. } \\
\text { - The editor provided in the tool } \\
\text { is meant for HTML/CSS text } \\
\text { adaptation only yet learning } \\
\text { objects may contain other } \\
\text { assets (like images and Java } \\
\text { applets) where the learning } \\
\text { may be centered but won't be } \\
\text { adapted. }\end{array}$ \\
\hline
\end{tabular}

The challenge at hand is that the current tools available for learning object adaptation are format-specific, yet learning objects retrieved from the repository may not necessarily be of that particular format supported by the tool [16]. For example, the current learning object adaptation tools tend to assume that every learning object is written in either HTML 
or XML and delivered in a web-based environment(like the Wiki-Type Content Editor [16]), which is not always true. This means that to use such a tool requires the instructional designer to first convert the learning object into a format that is supported by the tool and later re-formats the adapted learning object to its original format for easy integration with other learning objects. These round-trip format conversions are likely to cause the loss of key information in the learning object.

The Table I below is a summary of the review of three existing tools for adaptation of learning objects (whose characteristics are within the scope stated in section I above).

The Fig. 1 below shows a model for the underlying process for adaptation of learning objects used by the current techniques.

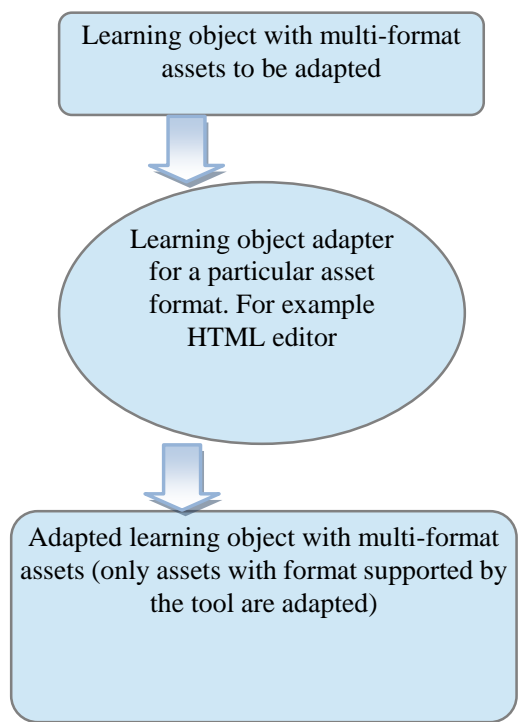

Fig. 1. A model for the underlying process for adaptation of learning objects used by the current techniques/tools.

\section{PROPOSED MODEL FOR AdAPTATION OF LEARNING OBJECTS WITH MULTI-FORMAT ASSETS}

The proposed model is made up of three components, namely; the learning object decomposer, learning object asset adapter and learning object asset assembler. The proposed model advocates for adaptation at asset level and below is a brief description of the components of the model.

\section{A. Learning Object Decomposer}

This component takes the learning object and decomposes it into its different assets.

Decomposition of a learning object into its assets largely depends on the granularity of that learning object and also how tightly-coupled the assets are. The learning object's assets are indecomposable (since they are considered as "atoms" that make up the learning object) but can be reused on "as is" basis, although customizations can be done on them like presentation and style. Decomposing a learning object is not simply breaking it into a bunch of tightly-coupled assets, care must be taken to ensure that the assets do not loose their pedagogical sense and any asset dependences must be considered.

Existing software decomposition techniques in Component-Based Software Engineering (CBSE) like divide and conquer, top-down decomposition, among others can be employed to decompose a learning object into its assets. This should be possible since a number of scholars (such as Menendez and Prieto [19], Todorova and Petrova [20], and Gomez et al. [21]) consider the term learning object to be analogous to software component as used in Component Based Software Engineering (CBSE).

The requirements to this learning object decomposer in the proposed model are that the structure of the learning object to be decomposed into assets must be expressible in XML(eXtensible Markup Language) and must as well have characteristics earlier stated in section I of this paper.

\section{B. Learning Object Asset Adapter}

An asset adapter in this case is a tool or technique that is applied to the individual asset of the learning object to enable it to contribute to the learning object in achieving a new learning objective. Each asset format has a corresponding adapter (as shown in Fig. 2).

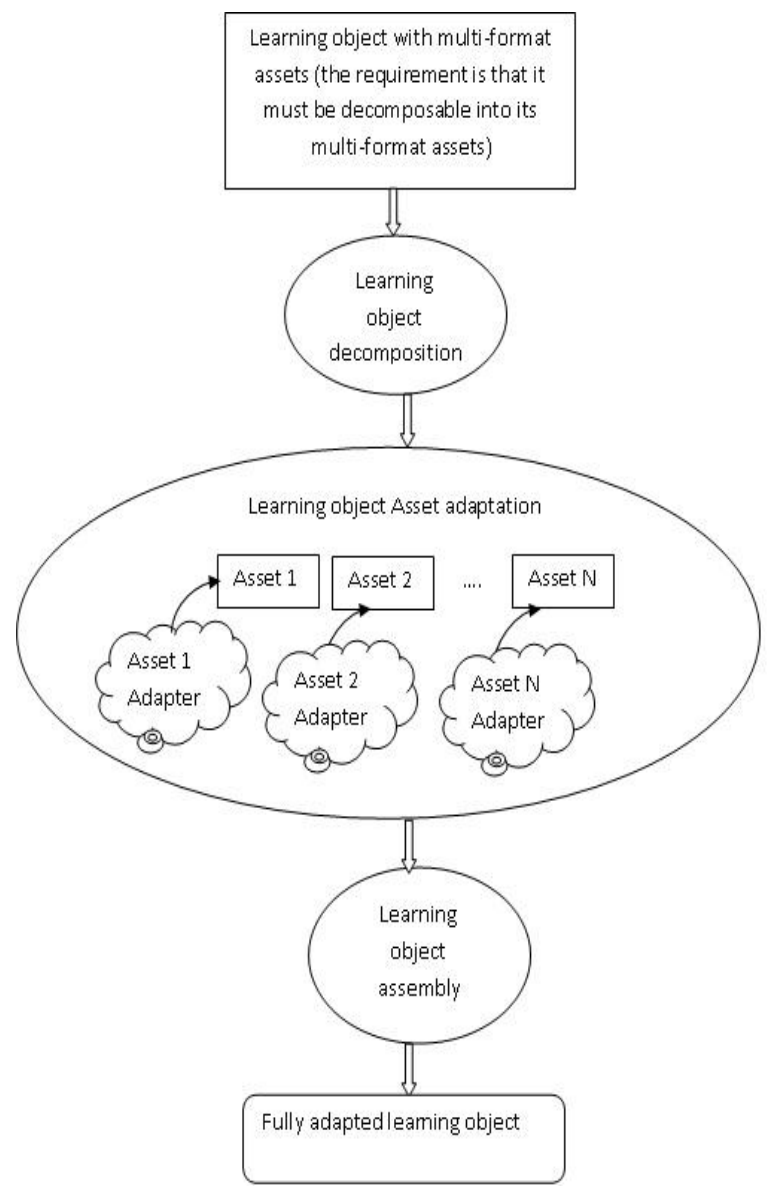

Fig. 2. The proposed model for full adaptation of learning objects with multi-format assets.

Although a learning object's assets are indecomposable, modifications can be done on the presentation, style and functionality. This would be adaptation of the learning object's assets. However, adaptation of the functionality of the asset largely depends on the transparency of the asset [6].

Generally, in learning object asset adaptation, given a set $L$ of the learning object's assets from the decomposer, we seek a set of asset adapters $T$ to apply on $L$ so as to produce $L^{\prime}$ which is a set of adapted assets to be assembled into a complete learning object that achieves a new learning objective. In other words, given that; 


$$
\begin{aligned}
& L=\left\{I_{1}, I_{2}, I_{3}, \ldots, I_{n}\right\} \text { and } \\
& T=\left\{t_{1}, t_{2}, t_{3}, \ldots, t_{k}\right\}, \\
& \text { Then } L^{\prime}=\left\{I_{1}, I_{2}^{\prime}, I_{3}^{\prime}, \ldots, I_{n}^{\prime}\right\}
\end{aligned}
$$

where $t_{1}$ is an adapter for all assets of the learning object that have the same format as $l_{1}, t_{2}$ is an adapter for all assets of the learning object that have the same format as $l_{2}$, and so on.

\section{Learning Object's Asset Assembler}

This component takes the adapted learning object's assets and assembles them into a new learning object (that achieves a new learning objective) following instructional design principles as desired by the instructional designer who wants the adapted learning object.

\section{CONCLUSION AND FUTURE WORK}

The review of the existing tools/techniques for adaptation of learning objects shows that they are format specific and thus can not fully adapt a learning object with multi-format ssets. The proposed model aims at ensuring that each of the assets of the learning object is adapted. Future work focuses on implementation, testing and validation of the proposed model. Future work also looks at how the proposed model can support learning object adaptation at metadata level so that learning objects based on different metadata standards can be integrated with ease.

\section{ACKNOWLEDGEMENT}

Special thanks go to International University of East Africa (IUEA) - Kampala Uganda, for sponsoring the registration of this publication. May God bless you abundantly.

\section{REFERENCES}

[1] D. A. Wiley. (2007). Connecting learning objects to instructional design theory: A definition, a metaphor, and a taxonomy. The Instructional Use of Learning Objects. [Online]. Available: http://reusability.org/read/chapters/wiley.doc

[2] A. L. Chiappe, Y. S. Cifuentes, and H. Y. R. Rodriguez, "Towards an instructional design model based on learning objects," Education Technology Research Development, vol. 55, pp. 671-681, 2007.

[3] IEEE Standard for Learning Object Metadata, Standard No.: 1484.12.1-2002.

[4] Reusable Learning Project. (2014). Granularity of Digital Resources. [Online].

Available: http://www.reusablelearning.org/about/Granularity.html

[5] J. E. Agaba and J. T. Lubega, "On addressing design issues that hinder reusability of learning objects in instruction design," International Journal of Information and Education Technology, vol. 4, no. 1, pp. 25-28, February 2014.

[6] J. E Agaba, B. Kanagwa, D. Tuheirwe, and S. Lunkuse, "Improving Learning objects reusability through automatic generation of web services," presented at 7th International Conf. on Computing and ICT Research, August 2011.
[7] S. R. Schach, Object-Oriented and Classical Software Engineering, New York: McGraw-Hill, Inc, p. 216, 2007.

[8] Centurion Enterprises. Software Reusability. [Online]. Available: http://centurion2.com/SEHomework/SoftwareReusability/SoftwareRe usability.html

[9] J. Sanz-Rodriguez, J. M. Dorero, and S. Sanchez-Alonso, "Metrics-based evaluation of learning object reusability," Software Quality Journal, Springer, August 2010.

[10] X. Ochoa and E. Duval, "Measuring learning object reuse," in Proc. the 3rd European Conference on Technology Enhanced Learning: Times for Convergence, Springer-Verlag, vol. 5192, 2008, pp. 322-325.

[11] X. Ochoa and E. Duval, "Quantitative analysis of learning object repositories," IEEE Transactions on Learning Technologies, vol. 2, no. 3, 226-238, 2009.

[12] G. T. Heineman. (1999). Adaptation of Software Components. A WPI SERG Technical Report, February 1999. [Online]. Available: http://www.cs.wpi.edu/heineman/papers/CBSE2-wkshp.htm

[13] G. T. Heineman and H. O. Ohlenbusch, "An experiment in component adaptation," presented at ICSE, 2000.

[14] mEducator Project. (2012). Multi-type content repurposing and sharing in medical education. [Online]. Available: http://www.meducator.net/

[15] R. Devshri, S. Sudeshna, and G. Sujoy, "A comparative study of learning object metadata, learning material repositories, metadata annotation \& an automatic metadata annotation tool," Advances in Semantic Computing, vol. 2, pp. 103-126, 2010.

[16] C. Wang, K. Dickens, H. C. Davis, and G. Wills, Community Tools for Re-purposing Learning Objects, EC-TEL 2007, Berlin, Heidelberg: Springer-Verlag, pp. 378-392.

[17] S. Gkatzidou and E. Pearson, "A vision for truly adaptable and accessible learning objects," presented at ASCILITE, 2008, Melbourne.

[18] D. Gorgan, T. Stefanut, and V. Bacu, "eGLE GiSHEO elearning environment," presented at ESA-ESRIN, Frascati, Italy, September 6, 2010 .

[19] V. H. Menendez and M. E. Prieto, "A learning object composition model," Lecture Notes in Business Information Processing, vol. 5, no. 3, pp. 469-474

[20] M. Todorova and V. Petrova, "Learning objects," presented at the International Conference on Computer Systems and Technologies, 2003.

[21] J. M. Gomez, G. Alor-Hernandez, R. Posada-Gomez, I. Rivera, M. Mencke, J. Chamizo, F. G. Sanhez, and I. Toma, "An approach for component-based software composition," in Proc. Conference on Electronics, Robotics and Automotive Mechanics, 2008, pp. 195-200, IEEE Computer Society.

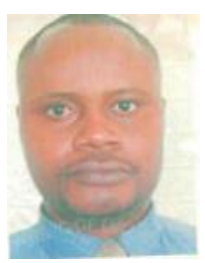

Joab E. Agaba is a $\mathrm{PhD}$ candidate at Makerere University. He held his master degree in computer science, and his bachelor degree in science from Makerere University. His main research interests are in e-learning and instruction design using learning objects.

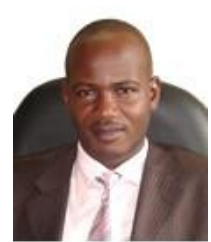

Jude T. Lubega is the deputy vice chancellor of Uganda Technology and Management University and a seasoned researcher. He held a $\mathrm{PhD}$ in information technology from University of Reading. His main research interests are in e-learning and instruction design using learning objects. 